\title{
The Generation X Faculty is Arriving!
}

\author{
Libby V. Morris
}

Published online: 26 August 2011

(C) Springer Science+Business Media, LLC 2011

It's that time of year again. Across small and large, urban and rural, commuter and residential institutions, students and faculty are preparing for the beginning of the academic year. Syllabi are updated, enrollments confirmed, classrooms assigned, faculty meetings set, students advised, committees formed, and the list goes on. During the summer months, some faculty members travel to distant locations for research or vacation. Others teach courses on campus or lead study abroad. I always imagine that some enjoy 8-10 weeks of leisure, reading novels and exploring new hobbies and recreation. I have yet to find that person of leisure; instead, all are busy trying to balance faculty work with personal or family time.

A small percentage of the faculty are not "returning", but rather they are "beginning"either launching or relocating a career to another college or university. For these new arrivals, no matter how seasoned, the new location may be both exciting and frustrating as they encounter new colleagues, policies, practices, students, and culture-only the disciplinary or professional knowledge remains constant in this new location.

Like many other institutions, the University of Georgia attempts to ease the transition with a faculty orientation held in the fall. These new colleagues represent various types of appointments: tenured and tenure track, lecturers, public service faculty, research associates, and so on. With 15 colleges and schools, representing virtually every discipline, field, and profession, the mix of new faculty joining the University of Georgia annually is quite diverse. Accordingly, in the orientation, we cover a wide variety of topics in short modules presented by the responsible head/leader (e.g., faculty governance, research, instruction, technology, Center for Teaching and Learning, legal affairs). If a session is totally unrelated to the faculty member's interest, at least it is short; and everyone hears a brief overview and is pointed in the direction of web resources and people resources. Apparently, the topics were mostly relevant, for at the end of the day, the 100-plus new faculty members remained enthusiastic; and, at the reception, the deans and other administrators mixed happily among the new recruits.

I did notice that a majority of the new faculty were part of Generation X (1964-1980). So, I was pleased that we had a member of our Teaching Academy to present on work/life

L. V. Morris $(\bowtie)$

University of Georgia Athens, Athens, GA, USA

e-mail: lvmorris@uga.edu 
balance, which according to several sources (Helms 2010) is of primary importance to this younger segment of the professoriate. A panel of junior faculty also shared tips on living in Athens with advice on food (grocery stores to fine restaurants), entertainment (night clubs, sports, and the like), to child care and other quality of life issues. I must admit I was surprised at the interest in these topics. A decade ago, I do not think that junior faculty or newly arriving faculty were quite so open about their personal lives for fear it would give the impression of not being scholarly or serious. These panelists are highly productive, and the joy of work and life combined showed in their comments and banter.

Generation $\mathrm{X}$ faculty, according to research from the Collaborative on Academic Careers in Higher Education (Helms 2010), seek quality over quantity in research, are less formal with students and interact significantly with them in and out-of-class, are interested in interdisciplinary work, and are highly comfortable with technology. The comfort with technology was clearly evident at our new faculty orientation when the quick review on technology opportunities at UGA barely raised an eyebrow of surprise - the technologies were all familiar, or so it seemed. Overall, the incoming faculty members have stellar vitas; and I was struck by the diversity of interests and accomplishments as I moved throughout the day meeting as many as possible.

My concern now is how to keep the momentum and the feeling that this was the right decision both professionally and personally for this newest faculty "cohort". What can be done formally and informally to enrich their lives and work? Mentoring in all of its dimensions would certainly be central to integrating the new faculty and to enhancing the opportunities for success. Within an institution, colleges and departments tend to have their own cultures and practices to incorporate new faculty members. Mentoring does indeed vary across programs and units: some have formal programs with assigned advisors, some are less formal with the new faculty selecting a person, and some likely still believe in the competition model or sink-or-swim approach.

A recent article in the Chronicle of Higher Education (Gose 2011) illustrated the diversity in mentoring practices, from providing life and emotional support to scholarly support. Mentoring may take place with a senior person within the department offering career and departmental advice, or with a faculty member within the institution but outside the department who can provide a separate institutional perspective, or sometimes even with a mentor at another university who may reflect on disciplinary and research-based advice and encouragement.

Beyond effective mentors, institutions are looking for other ways to support and encourage the new generation of faculty. Worthy of consideration are the five steps recommended by The Collaborative on Academic Careers in Higher Education (COACHE) to support the Generation X faculty: (1) provide opportunities for interdisciplinary work; (2) examine tenure policies (Is quantity valued over quality?); (3) ask for Generation X faculty input on established formal mentoring programs on campus; (4) support strategies to assist with work-life balance; and (5) build community by supporting opportunities for interaction, formal and informal, work and leisure. To me, it seems that these might be appropriate for incoming and returning faculty at most any stage of their careers. Moreover, these five steps could be the beginning of an interesting campus-based research project. Do these five steps really matter to Generation X faculty, for all faculty, on a specific campus or broadly? Perhaps action research would provide additional insight for institutional policy reform. To even the casual observer, Generation X faculty approach their careers and worklife balance differently from other generations. I believe there is much they can contribute to enhancing the quality of the academic environment for the future.

Here is to a productive and satisfying year in the academy! 


\section{References}

Gose, B. (2011, July 24). Junior professors: Juggling teaching, research, and advice. The Chronicle of Higher Education. Retrieved from http://chronicle.com/article/Junior-Professors-Juggle/128300/

Helms, R. M. (2010). New Challenges, new priorities: The experience of Generation X faculty. Harvard University Graduate School of Education, The Collaborative on Academic Careers in Higher Education. Retrieved from http://isites.harvard.edu/fs/docs/icb.topic436591.files/COACHE_Study_NewChallenges NewPriorities_20100304.pdf 